\title{
LIGHTWEIGHT STRUCTURES FROM THE PERSPECTIVE OF FORM FINDING FOR ARCHITECTS AND DESIGNERS
}

\author{
Sabah Shawkat \\ Assoc. Prof., PhD., Academy of Fine Arts and Design in Bratislava, SLOVAKIA, shawkat@vsvu.sk
}

\begin{abstract}
Architecture always reflects the requirements of the time. The revolutionary progress in science and technology pushes the boundaries of technical unfeasibility. Construction and technological methods now often determine the architecture of the building. New technologies allow to realize structures that have larger spans and are more and more light. The differences between design, construction and its characteristic form are disappearing. Lightweight structures represent one of the popular architectural forms of today construction and design. They appeal especially by their non-traditional solution and exceptional shape. The concept of lightweight structures is very interesting for the needs of architects or designers from the view of Form Finding.

Architects and engineers are studying, improving, and discovering. They are the creators of new spaces, forms, and structures. One category of them are lightweight structures that are seen in different forms, shapes, sizes, and variations in a broad spectrum of use. These structures developed over the years and together with advances in material engineering and technology they continue to progress. Lightweight structures may be internal, external, permanent, temporary, large, small, supported, etc. Their unique forms have played an important role in contemporary architecture and design since the time they first appeared in the 1960s as part of the work of the world-famous German architect and engineer Otto Frei.
\end{abstract}

A typical feature of today's architecture is the unity of function, structure, and form. Contemporary buildings are a synthesis of two concepts: Art and structure. A construction designed logically, in conformity with the principles of structural engineering, is at the same time an aesthetic construction, one that we tend to call "nice architecture".

Designing lightweight structures is a complex task. Meeting all the technical criteria while bringing beauty and elegance to the space requires the unification of the role of an architect and an engineer. Every part is visible and constructive, relying on the proper functioning of all parts. At present, lightweight structures are an integral part of architectural creation. They transform the space by their untraditional solutions, exceptional shape, as well as subtle and elegant quality. The unification of the role of architect and engineer in designing lightweight constructions is a current trend and is known, for example, under the Archineer® brand.

The concept of lightweight structures has also initiated a new discussion in our educational activities, and we aim to increase the interest and popularize this topic among students of architecture and other related study fields.

Keywords: Lightweight Structures, Pedestrian Tensegrity Bridge, Membrane Structures 


\section{LIGHTWEIGHT PEDESTRIAN BRIDGES}

Lightweight structures transform the space by their untraditional solutions, exceptional shape, as well as subtle and elegant quality. Physical models of bridges on Fig. 1 and Fig. 2 are a nice example showing the relation between art and structural engineering. The advantage of lightweight structures is that all forces are nicely visible. Forces are a mechanical concept useful for engineers who want to size their structures and they are by nature visible. By differentiating clearly cables and struts, the model of foot bridge provides information on whether tension and compression is present. Therefore, the dimensions of the components such as tubes and size, arrangement of cables depends upon the material properties as well as on the level of tension resp. compression state.

As seen on the figures, lightweight tensegrity structures are fascinating as the gravity seems to be absent and the structure looks as floating in the air. The stability of the entire system ensures that the whole is in equilibrium which ensures its stability.

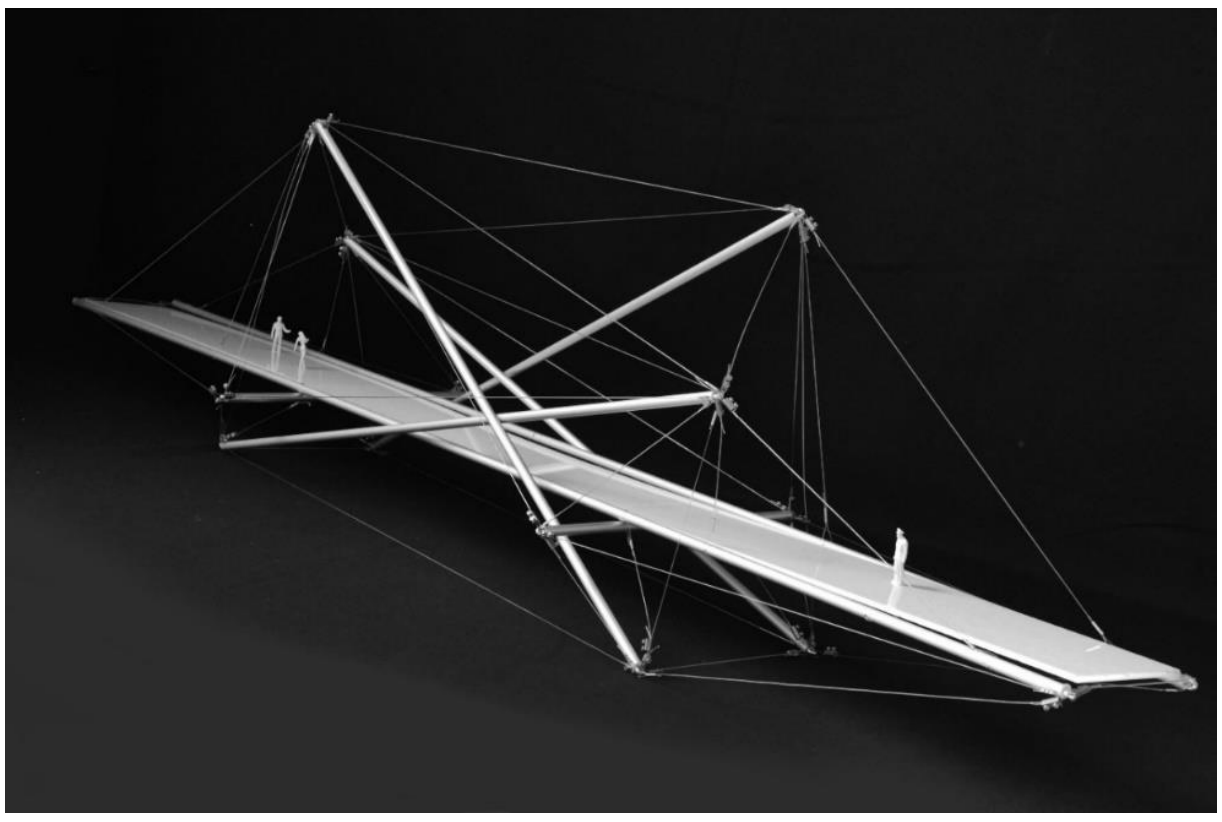

Fig. 1. Pedestrian Tensegrity Bridge (Shawkat, 2019)

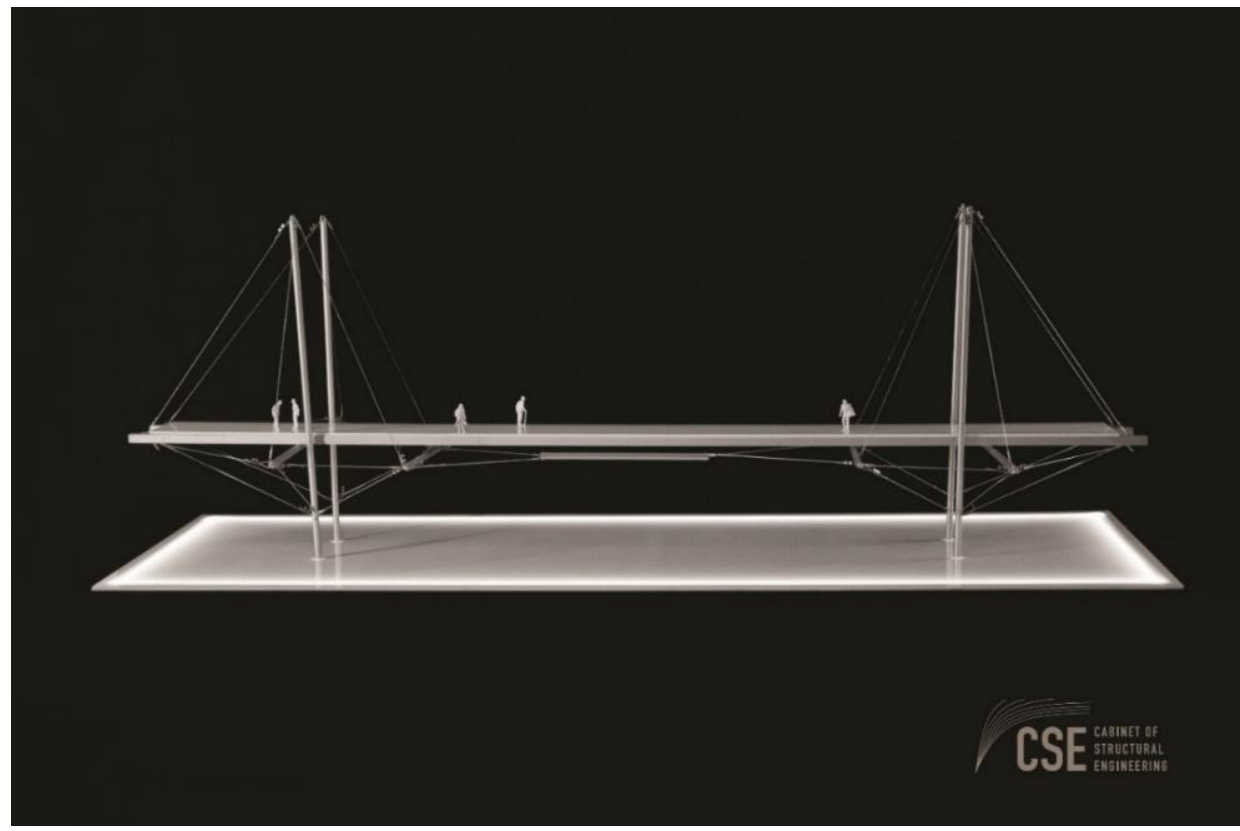

Fig. 2. Pedestrian Tensegrity Cable-stayed Bridge (Shawkat, 2019) 


\section{MEMBRANE STRUCTURES}

One of the extremely popular architectural forms of contemporary architecture and design represent the membrane structures Fig. 3. They appeal especially with their non-traditional solution, innovative design, unique shape, and great flexibility (Otto, Trostel, 1967 and Bach, 1988). Compared to traditional rigid structures they allow larger spans with minimal number of support members.

Membrane structure has always enjoyed great interest of students. Many different models of textile structures can be produced as physical miniatures of the static-structural system with large spans as shown in Fig. 4. The advantage of such models versus virtual $3 \mathrm{D}$ models is the possibility to directly verify the structural scheme.

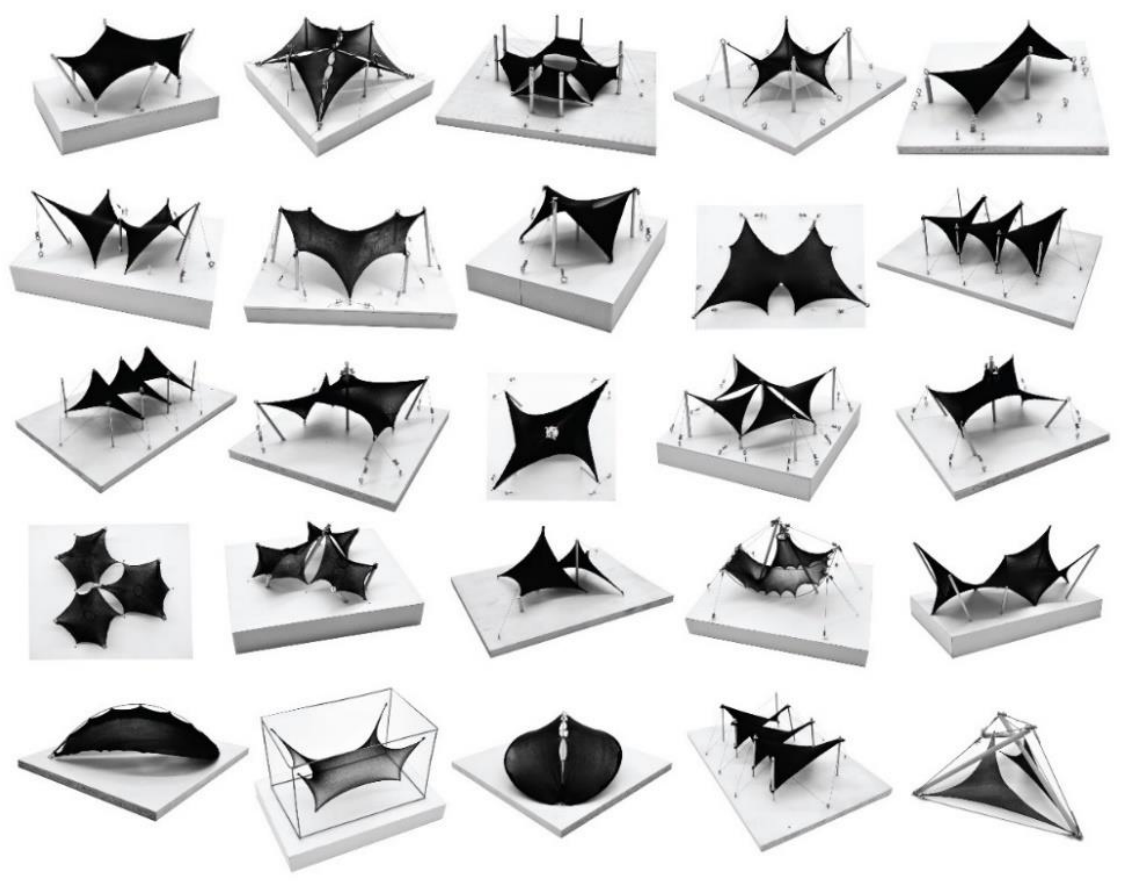

Fig. 3. Membrane Models, Small Scale Counts (Shawkat, 2021)

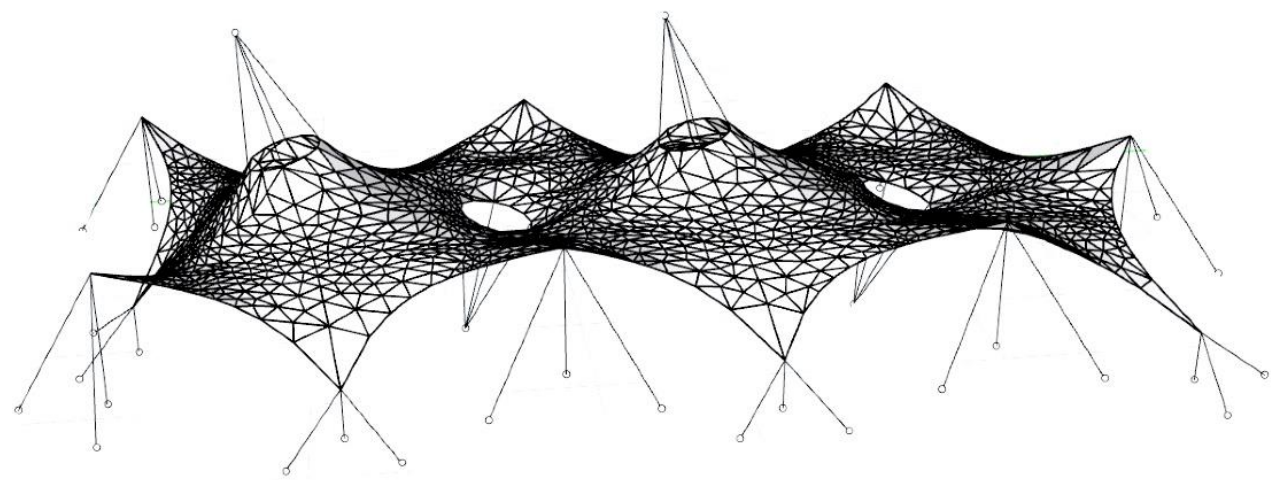

Fig. 4. Form Finding of Membrane Structures (Shawkat, 2021)

Instead of the term Membrane Structures, we can also come across designations such as Tensile Structures, Architectural Textile, Fabric Architecture or Textile Membranes. All these names refer to the same concept. 
From ancient times, people used textile constructions made of animal skins or fabrics, for example to create temporary dwellings or sails. As part of modern permanent structures, membrane structures began to be used in the 1960s, mainly due to the development of new technologies (Otto, Trostel, 1967). Today, membrane constructions are a common (and at the same time very aesthetic) part of various interior and exterior constructions and are used in every type of design. Exterior membrane constructions made of technical textiles are used as temporary (often mobile) or permanent light roof constructions of stadiums, arenas, cultural stands, shopping centres, exhibition halls, airports, amphitheatres, or as effective dominants of selected spaces. In interiors, textile membranes fulfil an aesthetic function and can also function as thermal or acoustic insulation.

\subsection{Types of Materials of Membrane Structures}

Membranes usually must fulfil both a load bearing and a roofing function at the same time and are therefore made of high-strength technical textiles. The tensile strength of the membrane material depends directly on the structure of the base fabric. The fabrics are usually made of glass fibres or of polyester, polyamide, polyvinyl alcohol and polyaramid fibres. To achieve higher strength and durability, the fabrics are coated and laminated with synthetic materials. The most used materials include polyvinyl chloride (PVC) laminated or coated polyesters and woven glass fibres coated with polytetrafluoroethylene (PTFE), known under the trade name Teflon or ethylene tetrafluoroethylene (ETFE). The coatings form protective layers of fibres and ensure that the membrane is impermeable to water (Foster, and Mollaert, 2004).

A great challenge for today's architects is global warming and membrane structures are increasingly seen in our territory as an integral part of sustainable climate solutions for public spaces and parks.

\subsubsection{Form Finding}

Form finding is the process of determining the equilibrium state of a membrane structure at a given level of prestress and selected boundary conditions. For the membrane structure to be able to efficiently transmit the corresponding effects of any load vector, its spatial surface must have the shape of a double curvature

(Otto, 1988). It can be achieved in three basic ways, which characterize the three most used types of membrane roofing Fig. 5:

1. hyperbolic paraboloid, which is achieved by fixing the membrane to four points, two of which are always at different levels. The flatter the saddle, the smaller the height distance between the upper and lower points, the greater the force effects arising in the corners of the system,

2. conical shape, which is achieved by fixing the membrane to the top of the column and at the bottom to the circular support ring,

3. arch - the membrane hanging between the arches situated in the transverse direction and in the lower longitudinal part is connected to the end ropes (Foster, and Mollaert, 2004).

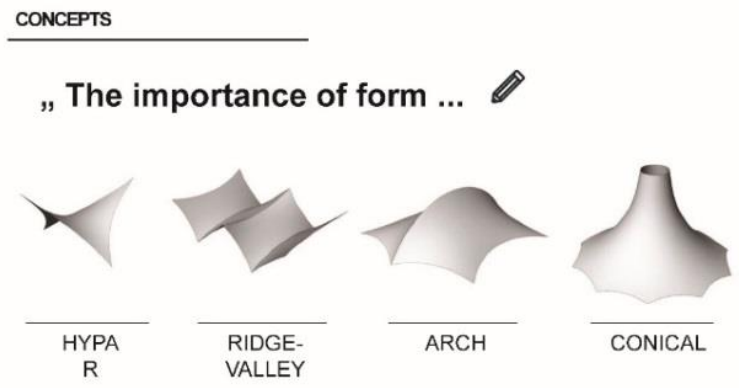

Fig. 5. Base Forms of Membrane Structures

\subsection{Advantages and Disadvantages of Membrane Structures}

The main advantages of constructions made of textile materials include their lightness (therefore they are also called lightweight structures), airiness and enormous flexibility. Compared to traditional rigid constructions, they make it easier to cover large spans with a minimum number of support elements (such as columns). Another plus is their design variability, providing almost unlimited possibilities for finding nontraditional elegant forms (Foster, and Mollaert, 2004). 
The latest materials have sufficient durability and permeability, as evidenced by their use in various climatic regions, from the Arctic winter to the desert heat. There are also materials that perfectly reflect sunlight, which can save a lot of electricity for cooling. Their unique light properties can also be used cleverly: during the day, thanks to their high transmittance, they make ideal use of daylight, and conversely, during the night, artificial lighting from the interior provides interesting exterior luminescence. Economically, membrane constructions are less demanding because they require only minimal maintenance compared to conventional constructions of similar dimensions.

The most important factor in large span structures is the relationship between sufficient distance and membrane joints. The largest span and the lowest stress on the anchoring and connection of membranes, allows greater economy of the structure. A very important factor is the quality of the joint. It is true that the more adapted the design details are to the real demands, the more durable the whole construction is and the less maintenance required.

When using membranes as a building material, it is important to pay attention to the long life and functionality of the membranes. Several problems that may occur include e.g., uneven thickness of the protective layer on the surface of the fibres, change in colour due to aging process, different elongation of the warp fibres or penetration of water into the fabric.

It turns out that the introduction of state of the modern technologies in connection with membrane structures allows this "light" concept to be promoted in others in areas where until now only heavy construction has dominated (Foster, Mollaert, 2004). For example, when creating an air-conditioned large space and a protected urban environment. Many buildings based on the principle of membrane structures belong not only to the original and creative in terms of architectural form, but they are also top technical works with a high level of technical detail.

\subsection{The Force Density Method}

The Force Density Method is popular among space structure designers and the method was developed at the end of the 1960s by German engineers Linkwitz and Schek for the determination of cable net structures or for the initial equilibrium problem of the cable roofs at the Olympic Games in 1972 hosted by Munich (Bletzinger, Wüchner, Daoud, Camprubi, 2005, and Bletzinger, 2014). Their goal was to determine a geometry that would be sufficiently rigid without the addition of load ballasts, geometry that would be built easily and would efficiently carry the loads over long distances using subtle elements. This method became very popular rapidly and designers began to work on research from various countries, which caused expansion and variation. Prestressed cable-nets structure and textile membranes are characterised by the inherent interaction between their geometry and stress distribution. This relationship between the form and forces makes it impossible to directly design such structures as is the case with conventional structures. Assumption for using this method is that, that the creating elements of the analysed structure, must be straight and must be pin joined to each other or to the supporting structure Fig. 6,7, which is fulfilled in this case (Bletzinger, 2014). First, a graph of a network is drawn, and all nodes are numbered from 1 to $N_{s}$, and all the elements are numbered from 1 to $\mathrm{m}$. The $\mathrm{N}_{\mathrm{f}}$ nodes which are to be fixed points are taken at the end of the sequence. All the other nodes $\mathrm{N}$ are considered as free. Thus, the total number of nodes is $\mathrm{N}_{\mathrm{s}}=\mathrm{N}+\mathrm{N}_{\mathrm{f}}$. Then the connectivity matrix $\mathrm{C}_{\mathrm{s}}$ is constructed with the aid of the graph. Each element $j$ has the node numbers $k$ and $I$ (from $k$ to $I$ ).

Looking at the geometric model of a typical node of the net, this node will be in a steady position, if the resulting force effect of the members will be in equilibrium with the external load in the node. On this basis, it is possible to construct the equilibrium rule for the node as follows: The element between the nodes $i$ and $j$ will be denoted by $(\mathrm{i}, \mathrm{j})$. The nodes that are linked with elements by the node $\mathrm{i}$ will be called "neighbours" to node $\mathrm{i}$, and the set of their labels will be denoted by $\mathrm{Ni}$. 


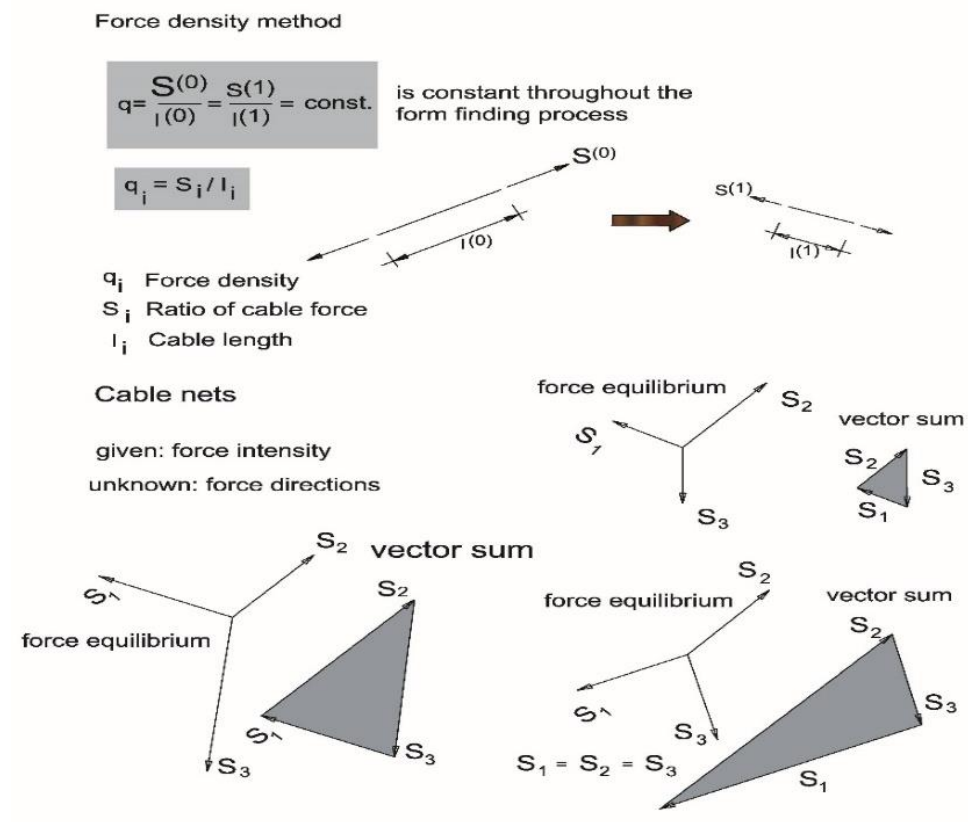

Fig. 6. Force Density Method (Bletzinger, 2014)

$N_{f} \cup N_{s}$ means the set of those elements which are either in $N_{f}$, or in $N_{s}$, or in both

$N_{f} \cap N_{s}$ means the set that contains all those elements that $N_{f}$ and $N_{s}$ have in common
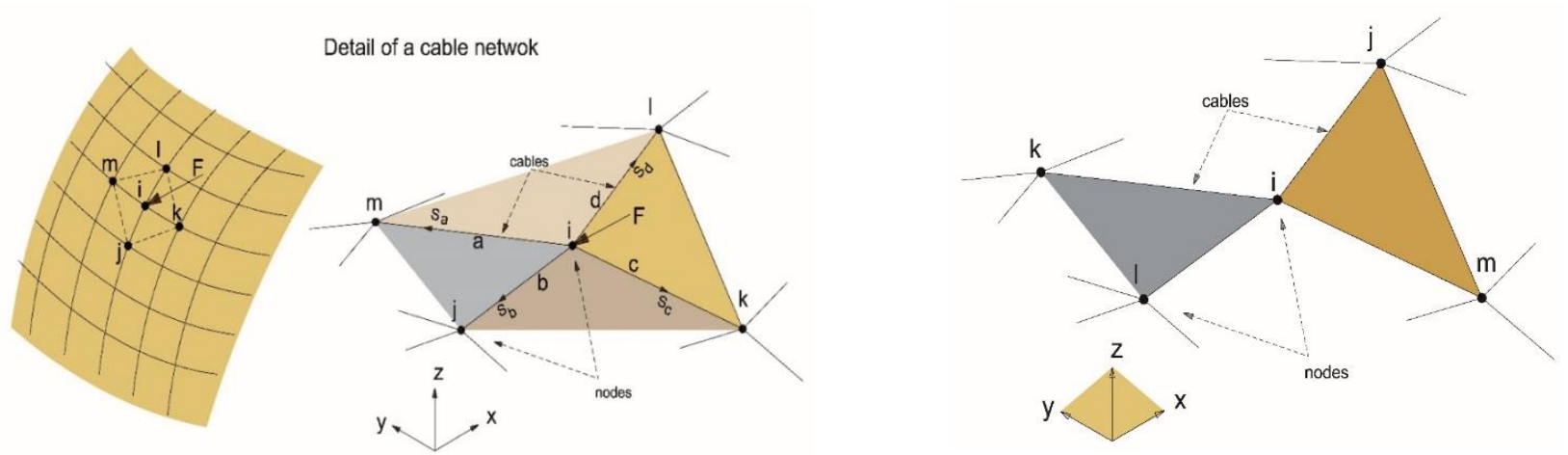

Fig. 7. Detail of Cable Network (Bletzinger, 2014)

By defining the positioning vectors $x_{s}, y_{s}, z_{s}$ from which are again based on the partial vectors related to the free node $x, y, z$ and related to the fixed node $x_{f}, y_{f}, z_{f}$, we can calculate the vector displacement of each node, in all directions of the global coordinate system,

$$
\mathrm{C}_{\mathrm{S}}=\left(\mathrm{C} \cdot \mathrm{C}_{\mathrm{f}}\right)
$$

where $C$ and $C_{f}$ contains the free and fixed nodes, respectively. Denoting the vectors containing the coordinates of the $n$ free nodes $x, y, z$, and similarly for the $N_{f}$ fixed nodes $x_{f}, y_{f}, z_{f}$, the coordinate differences for each element can be written as:

$$
\mathrm{u}=\mathrm{C}_{\mathrm{s}} \cdot \mathrm{x}_{\mathrm{s}}=\mathrm{C} \cdot \mathrm{x}+\mathrm{C}_{\mathrm{f}} \cdot \mathrm{x}_{\mathrm{f}} \quad \mathrm{v}=\mathrm{C}_{\mathrm{s}} \cdot \mathrm{y}_{\mathrm{s}}=\mathrm{C} \cdot \mathrm{y}+\mathrm{C}_{\mathrm{f}} \cdot \mathrm{y}_{\mathrm{f}} \quad \mathrm{w}=\mathrm{C}_{\mathrm{s}} \cdot \mathrm{z}_{\mathrm{s}}=\mathrm{C} \cdot \mathrm{z}+\mathrm{C}_{\mathrm{f}} \cdot \mathrm{z}_{\mathrm{f}}
$$

The equilibrium equations for the free nodes for the $\boldsymbol{x}$-, $\boldsymbol{y}$ - and $z$-directions are written as
(C) ${ }^{\mathrm{T}}$
$\cdot(\mathrm{U}) \cdot(\mathrm{L})^{-1} \cdot \mathrm{S}=\left(\mathrm{F}_{\mathrm{X}}\right)$
$(\mathrm{C})^{\mathrm{T}} \cdot(\mathrm{V}) \cdot(\mathrm{L})^{-1} \cdot \mathrm{S}=\left(\mathrm{F}_{\mathrm{y}}\right)$
$(\mathrm{C})^{\mathrm{T}} \cdot(\mathrm{W}) \cdot(\mathrm{L})^{-1} \cdot \mathrm{S}=\left(\mathrm{F}_{\mathrm{Z}}\right)$

By using the force-to-length ratios for the elements, i.e. the force densities, are written as: 

$(\mathrm{C})^{\mathrm{T}} \cdot(\mathrm{U}) \cdot \mathrm{q}=\left(\mathrm{F}_{\mathrm{X}}\right)$
$(\mathrm{C})^{\mathrm{T}} \cdot(\mathrm{V}) \cdot \mathrm{q}=\left(\mathrm{F}_{\mathrm{y}}\right)$
$(\mathrm{C})^{\mathrm{T}} \cdot(\mathrm{W}) \cdot \mathrm{q}=\left(\mathrm{F}_{\mathrm{z}}\right)$

where the vector $q$, of length $m$. is described as:

$(\mathrm{q})=(\mathrm{L})^{-1} \cdot(\mathrm{S})$

Modeling and analysis of membrane structures is a relatively demanding issue, especially when it comes to combining several element types, such as tension surface material with elements support structures. Only a model that will consider the real situation is relevant to the design of the real construction.

\section{REFERENCE LIST}

Shawkat, S. (2019). The Art \& Engineering of Lightweight Structures. Tribun EU, Brno, 308 pp.

Shawkat, S. (2021). Structural icons for architects, Tribun EU, Brno, 840 pp.

Otto, F., Trostel, R. (1967). Tensile Structures, vol 2, MIT Press

Bach, K., Burkhardt, B., Otto F. (1988). IL 18, Seifenblasen, Karl Kramer Verlag,Stuttgart, 400 pp.

Foster, B. (1998). The Integration of Large Fabric Structures within Building Projects including the Significance of Design and Procurement Methods. Proceedings of IASS - LSAA Symposium

Foster, B., Mollaert, M. (2004). European Design Guide for Tensile Surface Structures. Tensinet, Brussels.

Schleicher, S., Lienhard, J., Fleischmann, M. (2010). Forschungspavillon ICD/ITKE, Detail, online: http://www.detail.de/artikel forchungspavillonuniversitaet- stuttgart 26600 De.htm

Bletzinger, K.U., Firl, M., Linhard, J., Wüchner R. (2008). Optimal shapes of mechanically motivated surfaces.

In Computer Methods in Applied Mechanics and Engineering.

Bletzinger, K.U., Wüchner, R., Daoud, F., Camprubi, N. (2005). Computational methods for form finding and optimization of shells and membranes. In Computer Methods in Applied Mechanics and Engineering, Vol. 194

Bletzinger, K.U. (2014). Structural Optimization, Lecture Notes, TU Munich, Bletzinger, K.-U. Ramm, E. Structural optimization as tool for shape design, in: Hirsch, C. et al., (Eds.), Numerical Methods in Engineering 92, Elsevier, Amsterdam, New York, 1992 